\title{
PEMANFAATAN LIMBAH PADAT DAN CAIR TAPIOKA SEBAGAI BAHAN BAKU PLASTIK MUDAH TERURAI (BIODEGRADABLE)
}

\author{
Edza Aria Wikurendra, Akas Yekti Pulih Asih \\ ${ }^{1,2}$ Kesehatan Lingkungan, Universitas Nahdlatul Ulama Surabaya \\ Email: edzaaria@unusa.ac.id
}

\begin{abstract}
The present research utilizes tapioca solid waste obtained from the UD production remnants. $\mathrm{HH}$ in the area of Pesantren sub-district, Kediri City was transformed into biodegradable plastic or bioplastics. The process includes mixing sodium acetate (PA) and acetic acid (PA) solution. The materials (tapioca waste, liquid and starch as control) are heated with solvent, then dried with percentage of 100\%, 50\%:50\%, 100\%, 50\%: 50\% or comparable with 7,5gr: Ogr, $3.25 \mathrm{gr}: 3.25 \mathrm{gr}$, Ogr : 7,5gr, 3.25gr: $3.25 \mathrm{gr}$. From the test, the best treatment results could be used as bioplastic making research materials. Plastics produced from tapioca waste (liquid and solid) and varied with tapioca were obtained with tensile strength of 2,78-4,41 Mpa and elongation of 8,27-14,27\%. FTIR test results in all samples indicated functional cluster of $\mathrm{O}-\mathrm{H}, \mathrm{C}-\mathrm{H}, \mathrm{C}=\mathrm{O}, \mathrm{C}-\mathrm{O},=\mathrm{C}-\mathrm{H}$ as clusters of markers have been formed bioplastics. Plastics produced from tapioca waste (liquid and solid) and varied with tapioca were obtained with tensile strength of 2,78-4,41 Mpa and elongation of 8,27$14,27 \%$. The tapioca solid waste with tapioca mixture degraded faster with degradation percentage of $29.99 \%$ compared to plastics from other materials of $0.26 \%$ (sample 3), $21.19 \%$ (sample 2) and $14.61 \%$ (sample 1).
\end{abstract}

Keywords: Tapioca Solid Waste, Bioplastics, Biodegradable

\begin{abstract}
ABSTRAK
Penelitian ini memanfaatkan limbah padat tapioka yang didapatkan dari sisa produksi UD. HH yang berada di wilayah Kecamatan Pesantren Kota Kediri untuk dijadikan plastik yang mudah terurai (Biodegradable) atau bioplastik. Proses pembuatan bioplastik dilakukan dengan dilanjutkan mencampurkan natrium asetat (PA) ke dalam larutan asam asetat (PA). Pemanasan bahan (limbah tapioka yaitu ampas, cair dan pati tapioka sebagai kontrol) dengan pelarut kemudian dikeringkan. dengan persentase 100\%, 50\%:50\%, 100\%,50\%:50\%. Atau sama sebanding dengan 7,5gr:0gr, 3,25gr : 3,25gr, 0gr : 7,5gr, 3,25gr : 3,25gr. Bioplastik yang dihasilkan diuji dengan uji mekanik berupa uji tarik dan uji elongasi, Uji gugus Fungsi dengan FTIR dan Uji Biodegradibilitas. Dari hasil pengujian dilihat treatment mana yang paling baik hasilnya maka sampel tersebut dapat digunakan sebagai bahan penelitian pembuatan bioplastik. Plastik yang dihasilkan dari limbah tapioka (cair dan padat) maupun yang divariasi dengan tapioka didapatkan hasil dengan kuat tarik 2,78-4,41 Mpa dan elongasi 8,27-14,27\%. Hasil pengujian FTIR pada semua sampel menunjukkan adanya sebagai gugus fungsi O- $\mathrm{H}, \mathrm{C}-\mathrm{H}, \mathrm{C}=\mathrm{O}, \mathrm{C}-\mathrm{O},=\mathrm{C}-\mathrm{H}$ sebagai gugus penanda telah terbentuk bioplastik.. Limbah padat tapioka dengan campuran tapioka lebih cepat mengalami degradasi dengan persentase degradibilitas sebesar 29,99\% dibandingkan dengan plastik dari bahan lain masing-masing sebesar 0,26\% (sampel 3), 21,19\% (sampel 2) dan 14,61\% (sampel 1).
\end{abstract}

Kata kunci: Limbah Padat Tapioka, Bioplastik, Biodegradable 


\section{PENDAHULUAN}

Sampah plastik merupakan sampah yang sulit diurai yakni selama 1.000 tahun pada tanah dan 450 tahun pada air. Selain sampah plastik sulit terurai, sampah plastik juga bukan sampah organik sehingga berbahaya bagi lingkungan. Dalam mengatasi permasalahan sampah tersebut salah satunya adalah dengan teknologi pengembangan bahan plastik yang mudah terurai di lingkungan serta mudah hancur atau disebut bioplastik atau plastik biodegradable. ${ }^{1}$

Polimerisasi merupakan pembentukan dan penyusunan bahan dasar plastik (monomer) secara sambung-menyambung. Proses polimerisasi merupakan salah satu cara pembuatan plastik. Selain bahan dasar plasik (monomer), dalam proses pembuatan plastik juga terdapat aditif. Zat non plastik atau aditif berfungsi untuk memperbaiki sifat plastik berupa zat dengan molekul rendah. Warna, penyerap sinar ultraviolet, antioksidan, antilengket serta lainnya merupakan salah satu fungsi bahan aditif pada plastik. $^{2}$

Singkong (Manihot utilissima) disebut ketela pohon atau ubi kayu adalah pohon tahunan tropika atau subtropika. Singkong memiliki akar yang panjang yakni $50-80 \mathrm{~cm}$ serta garis tengah $2-3 \mathrm{~cm}$ apabila dilihat dari fisiknya. Panjang akar pada singkong berbedabeda sesuai dengan jenis singkong.

Produk industri pada saat ini banyak yang menggunakan bahan baku singkong seperti pada industri farmasi, tekstil, dan makanan. Salah satu yang banyak diketahui masyarakat bahwa singkong merupakan bahan baku makanan tradisional. Getuk, keripik, timus dan gemblong merupakan makanan tradisional yang berasal dari olahan singkong. Olahan singkong dapat digolongkan menjadi beberapa yakni tepung singkong/tapioka, singkong dikeringkan (gaplek) dan singkong fermentasi (tape/ peyeum).

Modifikasi bahan baku tapioka dapat digunakan sebagai bioplastik. Bioplastik dapat dibuat dengan menghidrolisis tapioka sebelum dijadikan bioplastik. Pelarut asetat atau amonia dipanaskan dengan suhu $40^{\circ} \mathrm{C}$ dengan ditambahkan 50gram pati tapioka serta $50 \mathrm{ml}$ pelarut, hal tersebut merupakan proses hidrolisis.

Komposisi film plastik yang dibuat adalah 7,5gram hasil pemanasan, aquades sebanyak $100 \mathrm{ml}$, ethanol $96 \%$ sebanyak $45 \mathrm{ml}$ serta gliserol sebanyak 1,2ml. Dari hasil tersebut secara umum film plastik yang dihasilkan cukup stabil dengan ketebalan $41,72 \mu \mathrm{m}$, nilai kuat tarik antara 27,01-217,7 kgf/cm2, dan kemuluran $(2,55-62,89 \%)^{3}$

\section{METODE PENELITIAN}

Penelitian yang dilakukan adalah penelitian eksperimental adalah penelitian yang dilakukan dalam skala laboratorium. Penelitian ini dilakukan di Laboratorium Poltekkes Surabaya dan di Laboratorium Departemen Fisika Universitas Airlangga. 


\section{Prosedur Pembuatan Plastik}

Proses pembuatan plastik dilakukan dengan cara mencampurkan bahan mentah kedalam larutan $\mathrm{pH}$ 7. Hasil bahan dan pelarut yang telah kering, dihaluskan dengan ukuran $200 \mu \mathrm{m}$ dan diambil 7,5 g dengan berbagai persentase.

Tabel 1. Massa Limbah Padat dan Cair Tapioka

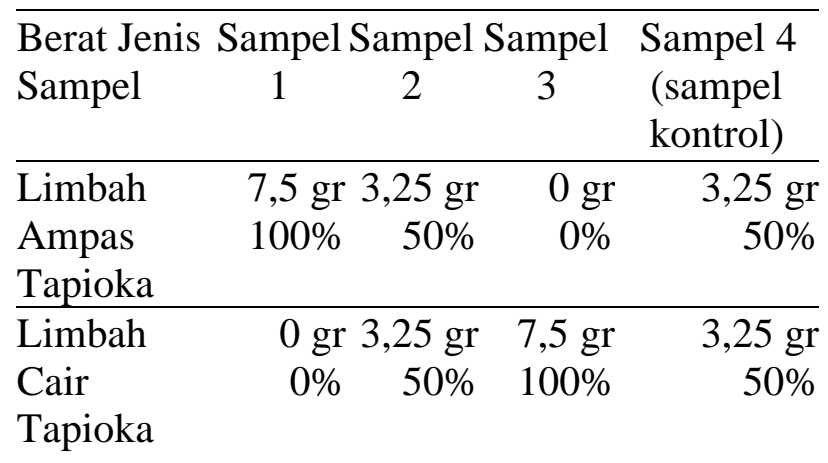

Sumber: Data Primer, 2019

Kemudian dimasukkan aquades ke dalam gelas beker $(250 \mathrm{ml})$ sebanyak $100 \mathrm{ml}$, ditambahkan ethanol 96\% sebanyak $45 \mathrm{ml}$ serta gliserol sebanyak 1,2 ml. Larutan tersebut kemudian dipanaskan pada hotplate magnetic stirrer sampai mengental dengan suhu kurang dari $70 \mathrm{oC}$ serta kecepatan $60 \mathrm{rpm}$. Setelah mengental dicetak diatas plexiglass $(20 \times 10 \mathrm{~cm})$ dengan ketebalan $1 \mathrm{~mm}$ dan didinginkan pada suhu ruang. Plastik yang dihasilkan berbentuk lembaran tipis.

\section{Metode Analisa Data}

Karakterisasi sampel yang akan dilakukan meliputi : Uji mekanik (uji tarik dan elongasi) serta uji gugus fungsional pada bioplastik dengan FT-IR Biodegradibilitas.

\section{HASIL DAN PEMBAHASAN}

Hasil penelitian beserta pembahasannya akan disajikan di bawah:

\section{Hasil uji kuat tarik dan elongasi}

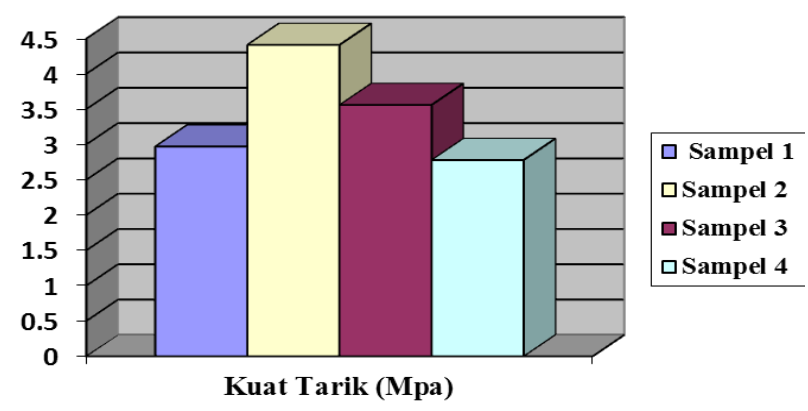

Gambar 1. Grafik Kuat Tarik Sampel Uji terhadap Jenis Sampel

Berdasarkan gambar 1 diketahui bahwa kuat tarik pada masing-masing sampel memiliki hasil yang berbeda dimana sampel 2 yang merupakan campuran antara limbah ampas tapioka dan limbah cair tapioka memiliki hasil paling tinggi dengan nilai 4,41 Mpa. Sedangkan untuk sampel 3 yang merupakan limbah cair didapatkan hasil 3,56 Mpa, sampel 1 dengan bahan limbah ampas tapioka didapatkan hasil 2,97 Mpa dan sampel 4 yaitu campuran antara limbah ampas tapioka dan tapioka memiliki hasil kuat tarik paling rendah yakni sebesar 2,78 Mpa.

Hasil uji kekuatan tarik pada gambar 1 menunjukkan bahwa nilai kuat tarik film plastik bergantung pada formulasi tertentu. Kekuatan serat akan dipengaruhi oleh proses penggilingan yang menyebabkan ikatan serat meningkat. Ketahanan tarik akan sedikit turun akibat 
rusaknya struktur serat akibat meningkatnya penggilingan yang berlebihan4. Kekuatan tarik akan meningkat apabila dilakukan penggilingan dengan tingkat tertentu.

Kondisi fisik film plastik setelah dicetak menunjukkan bahwa limbah cair tapioka maupun limbah ampas tapioka yang masih mengandung serat (selulosa) ini tidak tercampur dengan merata atai tidak homogen. Hal ini disebabkan proses penggilingan limbah ampas tapioka dan hasil dari limbah cair tapioka yang tidak sempurna. Pencampuran yang kurang sempurna dapat terjadi karena kadar serat yang banyak pada bahan sehingga berakibat pada film plastik yang tidak tercampur dengan baik atau tidak homogen, oleh sebab itu maka ikatan yang terjadi menjadi kurang kuat. Kekuatan tarik film plastik sangat terpengaruh oleh ikatan antar komponen tersebut.
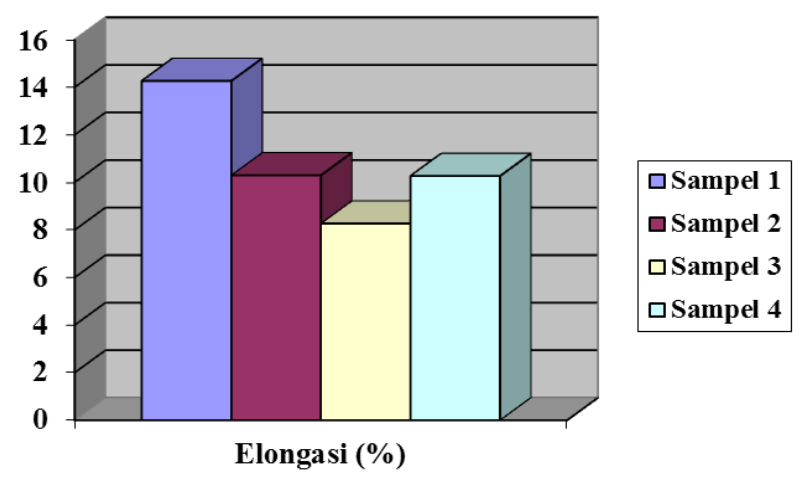

Gambar 2. Grafik Elongasi Sampel Uji terhadap Jenis Sampel

Berdasarkan gambar 2 didapatkan hasil grafik elongasi pada masing-masing sampel memiliki hasil yang berbeda dimana sampel 1 yang merupakan limbah ampas tapioka memiliki hasil paling tinggi dengan nilai elongasi $14,27 \%$. Sedangkan untuk sampel 2 yang merupakan campuran antara limbah cair dan limbah ampas tapioka didapatkan hasil elongasi 10,30\%, sampel 4 dengan bahan campuran antara limbah ampas tapioka dan tapioka didapatkan hasil elongasi 10,27\% dan sampel 3 yaitu limbah cair tapioka memiliki hasil elongasi paling rendah yakni sebesar 8,27\%.

Bahan pengisi kalsium karbonat yang tidak ditambahkan menyebabkan elongasi pada sampel menjadi besar. Ikatan hidrogen pada plastik akan semakin padat, kaku dan kuat akibat adanya bahan pengisi kalsium karbonat yang tinggi. Rapatnya jarak antar molekul menjadi penyebabnya. Semakin bertambah bahan pengisi yang dipakai maka nilai keelastisan plastik akan semakin turun.

\section{Hasil uji Faorier Transform Infra - Red (FT- IR)}

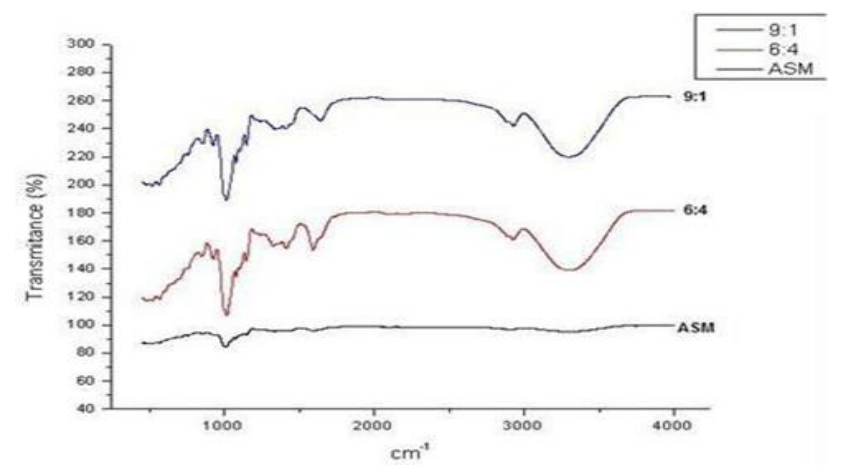

Gambar 3. Data Hasil dari Ampas Singkong Murni Uji FTIR

Gambar 3 diketahui belum terdapat adanya gugus fungsi di karenakan berbahan ampas singkong murni. 


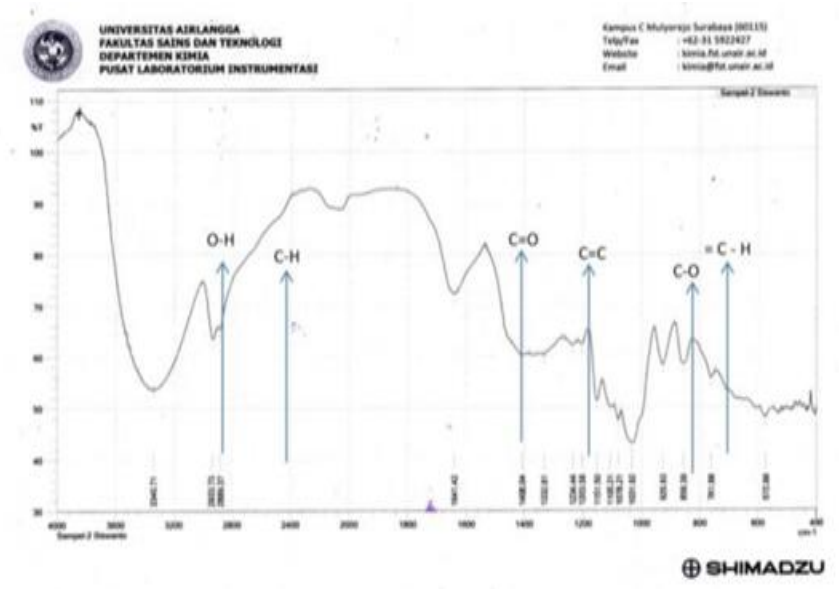

Gambar 4. Data Hasil Sampel 1 Uji FTIR

Gambar 4 merupakan sampel dengan bahan baku limbah ampas tapioka diketahui bahwa uji FTIR sampel limbah ampas tapioka memiliki ikatan gugus fungsi antara lain $\mathrm{O}-\mathrm{H}$, $\mathrm{C}-\mathrm{H}, \mathrm{C}=\mathrm{O}, \mathrm{C}=\mathrm{C}, \mathrm{C}-\mathrm{O}$ dan $=\mathrm{C}-\mathrm{H}$. Plastik akan mudah terdegradasi apabila memiliki gugus fungsi tersebut.

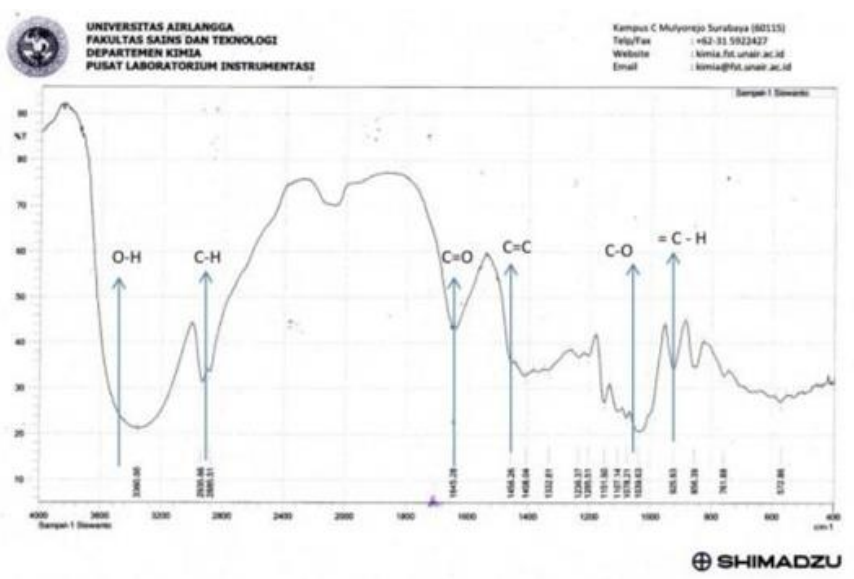

Gambar 5. Data Hasil Sampel 2 Uji FTIR

Gambar 5 merupakan sampel campuran antara limbah ampas tapioka dan limbah cair tapioka diketahui bahwa uji FTIR sampel limbah ampas tapioka memiliki ikatan gugus fungsi antara lain $\mathrm{O}-\mathrm{H}, \mathrm{C}-\mathrm{H}, \mathrm{C}=\mathrm{O}, \mathrm{C}=\mathrm{C}, \mathrm{C}-\mathrm{O}$ dan $=\mathrm{C}-\mathrm{H}$. Plastik akan mudah terdegradasi apabila memiliki gugus fungsi tersebut.

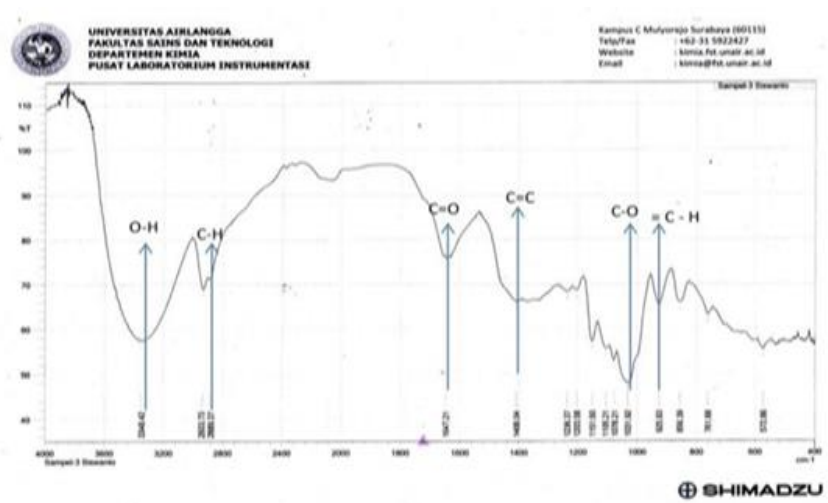

Gambar 6. Data Hasil Sampel 3 Uji FTIR

Gambar 6 yang merupakan sampel dengan bahan baku limbah cair tapioka diketahui bahwa uji FTIR sampel limbah ampas tapioka memiliki ikatan gugus fungsi antara lain $\mathrm{O}-\mathrm{H}, \mathrm{C}-\mathrm{H}, \mathrm{C}$ $=\mathrm{O}, \mathrm{C}=\mathrm{C}, \mathrm{C}-\mathrm{O}$ dan $=\mathrm{C}-\mathrm{H}$. Plastik akan mudah terdegradasi apabila memiliki gugus fungsi tersebut.

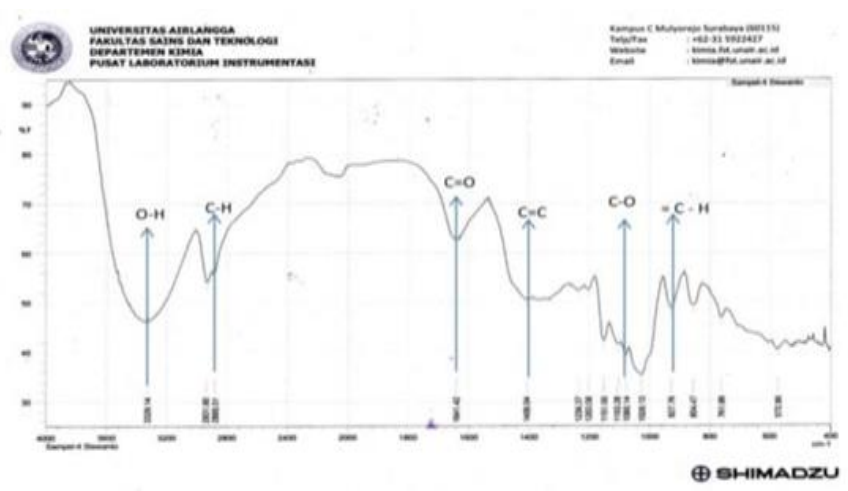

Gambar 7. Data Hasil Sampel 4 Uji FTIR

Gambar 7 merupakan sampel kontrol diketahui bahwa uji FTIR sampel limbah ampas tapioka dan tapioka diketahui bahwa uji FTIR sampel limbah ampas tapioka memiliki ikatan 
gugus fungsi antara lain $\mathrm{O}-\mathrm{H}, \mathrm{C}-\mathrm{H}, \mathrm{C}=\mathrm{O}, \mathrm{C}$ $=\mathrm{C}, \mathrm{C}-\mathrm{O}$ dan $=\mathrm{C}-\mathrm{H}$. Plastik akan mudah terdegradasi apabila memiliki gugus fungsi tersebut.

Pada gambar 4, 5, 6 dan 7 memiliki hasil yang sama dikarenakan kandungan kitosan sebesar $30 \%$ yang dipanaskan pada temperatur $95^{\circ} \mathrm{C}$ pada bahan bioplastik akan memiliki gabungan antara gugus fungsi dan gugus fungsi spesifik yang didapatkan dari komponen penyusunnya yakni pati dan kitosan. Seperti sifat penyusunnya yang hidrofilik (suka air) dapat terjadi dari proses blending secara fisika dari bahan plastik yang dihasilkan sehingga tidak ditemukannya gugus fungsi baru. Bioplastik ini dapat terdegradasi dengan baik karena terdapat juga gugus fungsi karbonil (CO) dan ester $(\mathrm{COOH})$ pada bahan bioplastik yang di uji dengan FTIR ${ }^{4}$.

Sejenis gaya tarik antar molekul yang terjadi antara dua muatan listrik parsial dengan polaritas yang berlawanan marupakan pengertian dari ikatan hidrogen. Ikatan ion dan ikatan kovalen jauh lebih kuat dibandingkan ikatan hidrogen ${ }^{5}$.

Apabila sebuah molekul memiliki atom $\mathrm{O}$, $\mathrm{N}$ atau $\mathrm{F}$ yang memiliki pasangan elektron bebas atau ione pair electron, maka akan terjadi ikatan hidrogen. Ikatan hidrogen terbentuk dari hidrogen dari molekul lain yang berinteraksi dengan pasangan elektron bebas. Plastik berkaitan dengan air dapat terjadi bila gugus $\mathrm{OH}$ ada pada jumlah yang banyak.

\section{Data hasil uji biodegradable}

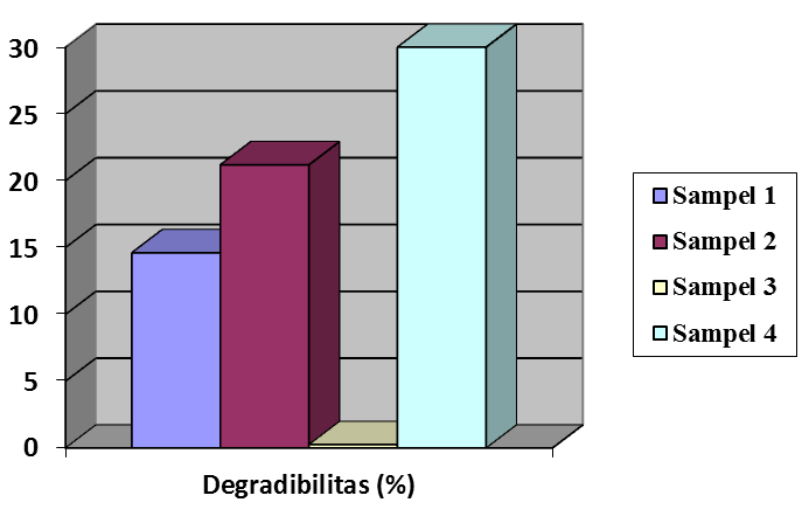

Gambar 8. Grafik Persentase Degradibilitas Sampel Plastik

Hasil uji biodegradable pada gambar 8 diketahui bahwa sampel 4 yang merupakan control dengan campuran bahan antara limbah ampas tapioka dan tapioka memiliki nilai degradibilitas tertinggi yakni sebesar 29,99\%, kemudian sampel 2 dengan bahan campuran antara limbah cair dan limbah ampas tapioka didapatkan hasil 21,91\%. Sedangkan untuk sampel 1 dimana bahan dari limbah ampas tapioka didapatkan hasil degradibilitas sebesar $14,61 \%$ dan yang paling rendah hasil uji degradibilitasnya adalah sampel 3 merupakan hasil bioplastik dari bahan limbah cair dengan nilai degradibilitas sebesar $0,26 \%$.

\section{SIMPULAN DAN SARAN}

\section{Simpulan}

Simpulan pada penelitian ini yakni limbah tapioka cair maupun padat dapat digunakan sebagai bahan dasar pembuatan bioplastik atau plastik yang mudah terurai (Biodegradable) 
dimana uji kuat tarik, elongasi, uji gugus fungsi, uji Faorier Transform Infra - Red (FTIR) dan uji biodegradibilitas masing-masing didapatkan hasil bahwa sampel 2 yaitu campuran antara limbah ampas tapioka dan limbah cair tapioka mendapatkan nilai tinggi pada hasil uji tersebut dibandingkan dengan sampel 1 ataupun 3 . Namun sampel 4 atau variabel kontrol memiliki hasil biodegradibilitas yang lebih baik dibandingkan sampel yang lainnya.

\section{Saran}

Menggunakan bahan yang PA dalam proses pembuatan plastik agar plastik yang diperoleh baik. Perlu penelitian lanjutan untuk meningkatkan sifat mekanik.

\section{REFERENSI}

1. Adiwijaya, M. Peran Pemerintah, Industri Ritel, dan Masyarakat dalam Membatasi Penggunaan Kantong Plastik sebagai Salah Satu Upaya Pelestarian Lingkungan. Artikel Fakultas Ekonomi, Universitas Kristen Petra : Surabaya, 1-8. 2011.

2. Rezki, D.I, Ratnawulan, dan Darvina, Y. Pengaruh Penambahan Senyawa Ekstrak Kulit Jeruk (Citrus SP) Terhadap Sifat Fisika Plastik Biodegradable Dari Ubi Kayu Dengan Senyawa Aditif Gula Jagung. PILLAR OF PHYSICS, Vol. 7. April 2016, 73-80. 2016.

3. Denia, P.A. Pengaruh Penambahan Selulosa Diasetat dari Serat Nanas Terhadap Sifat Mekanik Edible Plastik berbasis Pati Tapioka. Skripsi. Departemen Fisika dan Teknologi. Universitas Airlangga: Surabaya. http://repository.unair.ac.id/25605/. 2011.

4. Darni, Y., H. Utami dan S. Asriah. Peningkatan Hidrofobisitas dan Sifat Fisik
Plastik Biodegradable Pati Tapioka dengan Penambahan Selulosa Residu Rumput Laut Eucheuma Spinossum. Prosiding Seminar Hasil Penelitian dan Pengabdian Kepada Masyarakat. Universitas Lampung. $14 \mathrm{Hlm}$. 2009.

5. Firdaus, F. dan Anwar, C. Potensi Limbah Padat-Cair Industri Tepung Tapioka sebagai Bahan Baku Film Plastik Biodegradabel. LOGIKA, Vol. 1, No. 2, Juli 2004. ISSN: 1410-2315. 2004. 